\title{
COVID-19 in South Korea: Focusing on Club Infections
}

\author{
Moon-Jung Shim ${ }^{1}$ and Yun-Jung Kang ${ }^{2 *}$ (D) \\ ${ }^{1}$ Department of Clinical Laboratory Science, Ansan University, Ansan, Republic of Korea. \\ ${ }^{2}$ Department of Clinical Laboratory Science, Sangji University, Wonju 26339, Republic of Korea.
}

\begin{abstract}
On January 20, 2020, the first COVID-19 case in Korea was confirmed. The Korean government handled the situation by early identification and quarantine along with transparent disclosure of information, while announcing a National Guideline to practice aggressive prevention policies. Consequently, the government changed its social distancing policy into a casual-distancing-in-daily-lives policy. However, on the very day when the new policy started, a new male patient who had visited a club in Itaewon, Seoul, was confirmed to be the start of a club infection. This incident gave rise to three possible problems for Korea. Firstly, asymptomatic infection, which means a patient can spread the virus having only slight or no symptoms at all, can increase. Secondly, the fourth infection occurred due to local transmission by confirmed cases related to the club infection. Thirdly, the change in awareness among the 20 s and 30 s age groups is required to minimize the COVID-19 situation. As there is no established cure for COVID-19, both the government and the public should exert care.
\end{abstract}

Keywords: Change of awareness, Club infections, COVID-19, Fourth infection, Infection without Symptoms

*Correspondence: Ivpig@naver.com; +82-33-738-8081

(Received: November 23, 2020; accepted: December 03, 2020)

Citation: Shim M-J, Kang Y-J. COVID-19 in South Korea: Focusing on Club Infections. J Pure Appl Microbiol. 2020;14(4):22992302. doi: $10.22207 / J P A M .14 .4 .08$

(C) The Author(s) 2020. Open Access. This article is distributed under the terms of the Creative Commons Attribution 4.0 International License which permits unrestricted use, sharing, distribution, and reproduction in any medium, provided you give appropriate credit to the original author(s) and the source, provide a link to the Creative Commons license, and indicate if changes were made. 
Severe acute respiratory syndrome coronavirus 2 (SARS-CoV-2) first occurred in December 2019 in China and has spread through other countries in Asia, the Middle East, Western Europe, and North America. Recently, it has become a worldwide infection, affecting Eastern Europe, South Asia, and Africa. COVID-19 is a variety of coronavirus which was coined by WHO. Subsequently, the Korea Centers for Disease Control and Prevention named it Corona $19^{1}$. On March 11, 2020, when the number of confirmed cases worldwide reached 120,000, WHO declared COVID-19 to be on the highest level for an infectious disease, that is, a pandemic. SARS-CoV-2 is a type of Betacoronavirus with $86.9 \%$ genetic homology with bat SARS-like coronavirus, which originates from animals. There are four genera in Coronaviridae, the Family where SARS-CoV-2 belongs. Among them, the genera Alphacoronavirus and Betacoronavirus are capable of infecting people and animals. SARS-CoV and MERS-CoV under Betacoronavirus causes serious pneumonia ${ }^{2}$. Like most respiratory viruses, SARSCoV-2 is thought to be spread mainly in two ways: direct transmission through respiratory

Table 1. Status of COVID-19 infection in relation to club (00:00, May 17th)

\begin{tabular}{llll}
\hline \multicolumn{2}{c}{ classification } & cases & $\%$ \\
\hline \multicolumn{2}{c}{ Total } & 168 & 100.0 \\
Gender & Male & 136 & 81.0 \\
& female & 32 & 19.0 \\
age & $60 \leq$ & 5 & 3.0 \\
& $50-59 \mathrm{~s}$ & 6 & 3.6 \\
& 40-49s & 11 & 6.5 \\
area & 30-39s & 27 & 16.1 \\
& 19-29s & 102 & 60.7 \\
& 0-18s & 17 & 10.1 \\
& Seoul & 93 & 55.4 \\
& Gyeonggi & 33 & 19.6 \\
& Incheon & 23 & 13.7 \\
& Chungbuk & 9 & 5.3 \\
& Chungnam & 1 & 0.6 \\
& Busan & 4 & 2.4 \\
& Gyeongnam & 1 & 0.6 \\
Daejeon & 1 & 0.6 \\
& Jeonbuk & 1 & 0.6 \\
Gangwon & 1 & 0.6 \\
Jeju & 1 & 0.6 \\
\hline
\end{tabular}

[source] The Korea Centers for Disease Control and Prevention droplets of patients or indirect transmission by coming into contact with fomites in contaminated environments. The emission of virus from infected patients is thought to most likely occur immediately after symptoms develop ${ }^{3}$.

On January 20, 2020, the first COVID-19 case in Korea was confirmed. After this, the level of infectious disease warning was raised from "caution" to "alert" on January 27, and once the warning level was raised to "severe" on March 22 , a social distancing policy came into effect ${ }^{4}$. The Korean government handled the situation by early identification and quarantine along with transparent disclosure of information while announcing a National Guideline to practice aggressive prevention policies. Thanks to exemplary prevention policies, Korea has reduced the number of newly confirmed cases dramatically and stabilized the situation. Consequently, the government changed its social distancing policy into a casual-distancing-in-daily-lives policy. However, on the very day when this new policy started, a new male patient who had visited a club in Itaewon, Seoul, was confirmed to be the start of a club infection. From April 29 onward, the number of newly confirmed cases per day, which had been under ten, increased to 29 at 00:00 of May 11. At 00:00 of May 17, the total number of COVID-19 confirmed cases related to the club infection, were $168^{5}$. The Korea Centers for Disease Control and Prevention declared that 89 of the 168 cases were people who visited the club personally, and the other 79 were their close contacts, such as family, acquaintances, and colleagues. The biggest age group among the patients was people in their 20s, with more male than female patients (Table 1). Although the possibility of recurrent spread has gained attention as the number of confirmed cases per day in local communities increased due to the incident, the number has decreased to seven thanks to extensive COVID-19 detection related to clubs ${ }^{6}$.

Although it seems that we have avoided an explosive recurrent spread thanks to aggressive prevention measures, the club infection incident needs to be given great consideration. This incident gave rise to three possible problems for Korea. Firstly, asymptomatic infection, which means a patient can spread the virus with only slight or no symptoms at all, can increase. A study published in 
NEJM also confirms that COVID-19 can be infectious without showing symptoms. The PHSKC and CDC's COVID-19 team examined older citizens in medical care institutions, and $64 \%$ of the residents without symptoms were confirmed to be positive. Infections without symptoms were also confirmed in the club infection cases. According to the announcement of the head of the National Disease Prevention Headquarters, the infection rate by patients with slight or no symptoms is $30 \%$. Taking the number of young patients hidden in local communities into account, the number of infections without symptoms is likely to be higher. In other words, these patients are spreading the virus in their communities without knowing that they are infected. Secondly, the fourth infection occurred due to local spread by confirmed cases related to the club infection. A prison officer in a Seoul detention center and a 19-year-old high school student were confirmed to be positive. The confirmed case who visited the club infected a Karaoke, which became a source for infection and spread the disease to the visitor's colleague and the colleague's son. It took less than two weeks from the first patient's visit to the club to the fourth infection of the prison officer and the high school student ${ }^{7}$. This is an indication that COVID-19 related to the club incident has spread widely throughout local communities. Thirdly, the change in awareness among the 20s and 30s age groups is required to minimize the COVID-19 situation. On May 14, the accumulated number of confirmed cases was 10,991 , of which $38 \%$ were patients in their 20 s and 30 s. People in the age group of 19-29 years also occupied the largest proportion, at $60.7 \%$, of the club infection incidents. These people were socially active, widely moving, and social. It is true that the younger generation shows weaker symptoms even if they are infected by COVID-19; however, when they spread the virus to their family members, susceptible family members may die in severe cases. Additionally, young patients showing no symptoms can develop heart disease, have difficulty in breathing, experience changes in the immune system, and other side effects in the future. A survey conducted by the Graduate School of Public Health in Seoul National University showed that younger people are less aware of the danger of COVID-19. Thus, a government campaign targeting this age group is needed to raise awareness, as well as in people in their 20 s and $30 \mathrm{~s}^{8}$.

Clubs have poor ventilation, as they tend to have no windows, and are located in basements. Due to the volume of the music, people must be in close contact to facilitate communication. Dancing and drinking hinder them from wearing masks. From the early stages of the COVID-19 epidemic, experts warned against being in closed spaces and making intimate contact. Massive infection occurring in the clubs of Itaewon represented a typical case of closed spaces and intimate contacts combined. Considering the economic hardships and national fatigue, the timing of changing the prevention policy was apt. However, the problem was that the control was lifted uniformly, without considering the various levels of danger depending on the types of facilities. The level of danger depending on the types of facilities must be evaluated first, lifting the quarantine step-bystep from the lowest warning level upwards, and leaving the entertainment facilities like clubs at the end. As there is no established cure for COVID-19, both the government and the public should exert care.

\section{ACKNOWLEDGMENTS}

None.

\section{CONFLICT OF INTEREST}

The authors declare that there is no conflict of interest.

\section{AUTHORS' CONTRIBUTION}

The authors (MJ S., YJ K.) wrote the entire manuscript and holds final responsibility for the decision to submit the manuscript for publication. The authors read and approved the final manuscript.

\section{FUNDING}

None.

\section{DATA AVAILABILITY}

The datasets used and/or analyzed during the current study are available from the corresponding author on reasonable request.

\section{ETHICS STATEMENT}

Not applicable. 


\section{REFERENCES}

1. Korea Centers for Disease Control and Prevention; 2020 Feb 12 [cited 2020 May 17]. Available From:http://ncov.mohw.go.kr/tcmBoardView. do? brdld $=$ \&brdGubun=\&dataGubun=\&ncvContSeq= 352840 \& cont Seq = 352840 \& board. id $=140$ \&gubun $=B D J($ Korean)

2. Benvenuto $D$, Giovanetti $M$, Ciccozzi $A$, Spoto $S$, Angeletti S, Ciccozzi M. The 2019-new coronavirus epidemic: evidence for virus evolution. J Med Virol. 2020;92(4):455-459. doi: 10.1002/jmv.25688

3. Zou L, Ruan F, Huang M, et al. SARS-CoV-2 viral load in upper respiratory specimens of infected patients. N Engl J Med. 2020;382(12):1177-1179. doi: 10.1056/ NEJMc2001737

4. Korea Centers for Diseases Control \& Prevention. Infectious disease alert level [Internet]. Cheongju (KR): Korea Centers for Diseases Control \& Prevention, c2020 [cited 2020 Apr 17]. Available from: http://ncov.mohw.go.kr/tcmBoardView. do? brdld=3\&brdGubun=31\&dataGubun= \&ncrContSeq $=583 \&$ contSeq $=583 \&$ board
id=311\&gubun=ALL.

5. No JY. Corona 19 related to Itaewon Club 2 additional confirmers ... 168 in total. Kyunghyang Newspaper; 2020 May 17 [cited 2020 May 17]. Available from: http://news.khan.co.kr/kh_news/khan_art_view. html ?artid $=202005171454001 \&$ code $=940100$ (Korean).

6. Kim TH, Eum SJ, Lee YS, Lee YJ. Itaewon's 'explosive spread' has passed? Single digit on the second day of regional occurrence. New 1; 2020 May 17 [cited 2020 May 17]. Available from: https://www.news1. kr/articles/?3936860(Korean).

7. Kang YS. Time taken until the $4^{\text {th }}$ infection ' 13 days'... 60,000 inspections. MBC News; New 1; 2020 May 17 [cited 2020 May 17]. Available from: https://imnews.imbc.com/replay/2020/nwtoday/ article/5777069_32531.html

8. No JS. kinds of 'Corona 19 issues' sung by the club infection. Sisajournal; 2020 May 17 [cited 2020 May 17]. Available from: https://news. naver.com/main/read. $\mathrm{nhn}$ ? $\operatorname{mode}=L S D \& m i$ $\mathrm{d}=$ sec\&oid $=586 \&$ aid $=0000013708 \&$ sid $=001$ (Korean). 